\title{
Teatralidade e carnavalização. Zé Pereira no final do séc. XIX
}

[ Theatricality and carnavalization. Zé Pereira at the end of the century. XIX

\author{
Marcelo Fecunde de Faria ${ }^{\mathrm{I}}$
}

\section{Robson Corrêa de Camargo²}

RESUMO - Este artigo é parte de projeto de doutorado que investiga a carnavalização, as performances e as teatralidades lusobrasileiras nas manifestações que se intitulam Zé Pereiras. O texto examina as crônicas de Vieira Fazenda (I847-I9I7) e de Luís Edmundo (I878-I96I), cronistas do final do séc. XIX no Brasil. A análise busca aproximar os conceitos da teoria Bakhtiniana de análise do carnaval aos Zé Pereiras. Procura compreender a criação do personagem Zé Pereira, sua existência no carnaval brasileiro e o processo de higienização das festas de ruas. PALAVRASCHAVE - Teatralidade; carnavalização; performance. ABSTRACT - This article is part of a doctoral project that investigates luso-brazilians carnivals, performances, and theatricalities in the manifestations called Zé Pereiras. This text examines the writings of Vieira Fazenda (I847-I9I7) and Luís Edmundo de Melo Pereira da Costa (I878 - Rio de Janeiro, I96I), chroniclers of the late I9th century. XIX in Brazil. The analysis seeks to approximate the concepts of Bakhtin's theory of carnival analysis to Ze Pereiras. It exams the creation of the character Zé Pereira, its existence in the Brazilian Carnival, and the process of street party hygiene that took place at this festivity. KEYWORDS - Theatricality; carnavalization; performance.

Recebido em 25/08/2020

Aprovado em 27/09/202I

FARIA, Marcelo Fecunde de; CAMARGO, Robson Corrêa de. Teatralidade e carnavalização. Zé Pereira no final do séc. XIX. Revista do Instituto de Estudos Brasileiros, Brasil, n. 80, p. I42-I65, dez. 2O2I.

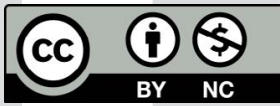

DOI: https://doi.org/Io.II606/issn.23I6-90IX.vIi8opI42-I65

I Universidade Federal de Goiás (UFG/PPGIPC, Goiânia, Goiás, Brasil).

2 Universidade Federal de Goiás (UFG/PPGIPC, Goiânia, Goiás, Brasil). 
José Nogueira de Azevedo Paredes é apontado na literatura do carnaval, pelos cronistas Vieira Fazenda (I847-I9I7) e Luís Edmundo de Melo Pereira da Costa (I878-I96I), como o precursor da manifestação carnavalesca chamada Zé Pereira, que daria início aos primeiros blocos de carnaval de rua no Rio de Janeiro (CUNHA, 2002; FERREIRA, 2004; MORAES, I987). Zé Pereira, a partir de I869, surgiu como esforço de uma afirmação sociocultural, e vai ser caracterizado como um grupo de indivíduos percussionistas que saem pelas ruas da cidade com bumbos, zabumbas, timbas e taróis, em tempos de carnaval. Os Zés Pereiras podem ainda ser encontrados com essa nomenclatura nos dias de hoje, em algumas regiões do Brasil (Goiás, Minas Gerais, Piauí, São Paulo, entre outras) e em alguns países da Europa - França, Espanha, com concentração maior em Portugal. Entre suas variações está principalmente a incorporação de mascarados, bonecos gigantes e gaitas de foles (MORAES, I987; FERREIRA, 2004; FARIA, 20I5).

$O$ final do séc. XIX no Brasil foi envolvido por mudanças radicais. O Rio de Janeiro fora cidade escolhida para ser o berço do modelo de civilização moderna. Apresentava tensões sociais e contrastes evidentes, de um lado uma classe urbanizada empregada no serviço público e no comércio e, de outro, uma classe marginal de escravos e desempregados que vivia em condições precárias (LOPES, I994). Essa "modernização" apontava para uma padronização que iria ser similar aos moldes civilizatórios europeus (reforma Pereira Passos no Rio de Janeiro no início do século XX, inspirada na reforma parisiense entre I853-I870). No Brasil colônia, o Rio de Janeiro, a maior cidade brasileira naquele momento, apresentava nas ruas as tensões da urbanidade que se adensava, entre os diferentes grupos sociais, com as difíceis condições de vida para a maioria da população e as diversidades de manifestações populares em oposição ao regime político, nas lutas antiescravagistas e pró-república ou em apoio ao formato existente.

No Rio de Janeiro, eclodiam a falta de local de moradia e, ao mesmo tempo, as habitações coletivas insalubres (cortiços), as epidemias de febre amarela, varíola, cólera, conferindo à cidade o apelido de "cidade da morte". Em I930, por exemplo, quase metade das mortes ocorridas no Brasil seriam ainda causadas por doenças infecciosas e parasitárias³. As reformas urbanas após a Proclamação da República

3 KALACHE, A. et al. O envelhecimento da população mundial. Um desafio novo. Rev. Saúde Pública, S. Paulo, v. 2I, p. 200-2Io, I987. 
procuravam o saneamento e o embelezamento do Rio de Janeiro, que será então chamado de cidade maravilhosa, moderna e cosmopolita.

As festas, nesse processo de mudança, e nas décadas seguintes, seguiriam em ritmo quente. Havia uma clara tensão social, o processo de higienização iniciado e os intelectuais da época faziam pipocar grupos diversos nos vários cantos do país, que se digladiavam, entre outras coisas, entre o ser ou não ser tupiniquins. As manifestações populares tiveram um papel importante nesse processo de mudança, pois, formadas em sua maioria pelas camadas mais pobres, conseguiriam construir a seus modos uma linguagem própria em cada grupo que satirizava o "de dia falta água e de noite falta luz”. O carnaval, a festa que consegue reunir diversas narrativas, brincadeiras, danças e grupos, tornou-se o símbolo tensionado, contradiscurso polifacetado dessa tentativa de construção de homogeneização cultural; era um destes espaços que não continha em si apenas uma festa, mas várias festas, várias visões de mundo e, por que não dizer, carnavais (CAVALCANTI, I999; QUEIROZ,I999).

\section{Carnavalização}

Acreditamos que o diálogo teórico com a abordagem de Bakhtin em relação ao conceito de carnavalização possa auxiliar-nos na realização de uma leitura acerca da caracterização do personagem social Zé Pereira retratado pelos cronistas. Os elementos essenciais (FIORIN, 20I9; DISCINI, 20I6) para analisar a carnavalização compõem-se de ambivalência, baixo material e corporal, mundo às avessas e realismo grotesco, os quais contribuem para destacar o termo nas manifestações populares, que Bakhtin atribuiu ao analisar a cultura popular na Idade Média e no Renascimento. Bakhtin (I987) desenvolveu o estudo com base na obra do autor renascentista François Rabelais ${ }^{4}$ (I494-I553), demonstrando que as festas carnavalescas, tanto medievais quanto renascentistas, apareceram como categorias importantes em manifestações que se opunham à cultura oficial. Assim, elas fazem parte de um conjunto de comportamentos que o autor define como a primeira categoria da cultura cômica: "as formas dos ritos e espetáculos (festejos carnavalescos, obras cômicas representadas nas praças públicas, etc.” (BAKHTIN, I996, p. 4). As festas carnavalescas tornaram-se importantes para o povo. As comemorações das manifestações do Carne Vale e, posteriormente, do Carnaval, eram formas concretas do riso popular e da manifestação da alegria.

A obra escrita em I940 e publicada em I965 foi capaz de revelar um mundo popular que momentaneamente fazia oposição à cultura oficial da época. Bakhtin nos dá três categorias para compreender o movimento dessa cultura: I - formas dos ritos e espetáculos; 2 - obras cômicas verbais; e 3 - diversas formas de gêneros do vocabulário

4 François Rabelais, pseudônimo Alcofribas Nasier (nasceu em I494, na França, e morreu, provavelmente, em 9 de abril de I553, em Paris), escritor francês e padre que, para seus contemporâneos, era um eminente médico e humanista e, para a posteridade, é o autor da obra-prima Gargantua e Pantagruel. Os quatro romances que compõem esse trabalho são notáveis pela riqueza renascentista francesa e pela comédia, que varia do burlesco à profunda sátira (http://global.britannica.com/EBchecked/topic/48794I/Francois-Rabelais). 
familiar e grosseiro. Ao longo de sete capítulos, o autor recupera a história do riso, em traços importantes para se pensar a obra de Rabelais a partir da cultura popular. A compreensão da cosmovisão carnavalesca da cultura foi inicialmente apresentada no capítulo IV da obra Os problemas da poética de Dostoiévski (20I3 [I963]), em que já podemos perceber os primeiros retratos dessa cosmovisão carnavalesca em voga. A carnavalização se faz no movimento circular da cultura, "é a transposição para a arte do espírito carnavalesco" (FIORIN, 20I9 [20I6], p. 97), das relações construídas entre autor, personagens e leitores em um dialogismo polifônico.

A trajetória do nosso personagem Zé Pereira na historiografia do carnaval brasileiro foi levantada por alguns pesquisadores, como ARAÚJO (2000), CUNHA, 200I, 2002; , FERREIRA (2004), GONÇALVES (2007), MORAES (I987), PINHEIRO (I995) e VALENÇA (I98I), que de alguma forma tentam datar sua passagem e demonstrar sua ação. Esses autores recontam, por meio de suas pesquisas, como teria sido a trajetória desse personagem icônico. Algumas revistas e jornais da época, entre I840 até o início do séc. XX, comprovam a popularidade do que se tornou uma expressão característica do carnaval no Rio de Janeiro: Semana Ilustrada, Jornal do Commercio, Revista Fon-Fon, entre outros.

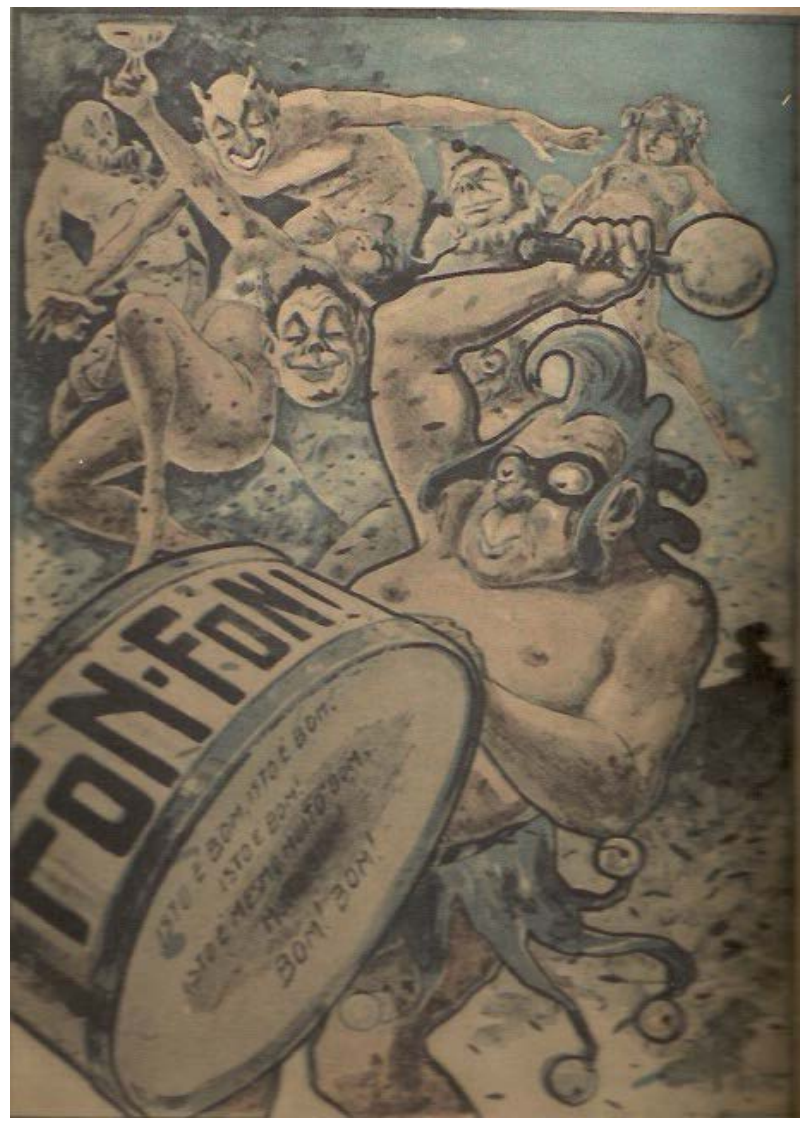

Figura I - Carnaval. Revista Fon Fon. ano III, n. 8, I8 de fevereiro de I909. 
Ao ler as crônicas escritas por Vieira Fazenda (I940) e Luiz Edmundo (2003), ambos considerados cronistas/memorialistas do Rio de Janeiro da virada do séc. XIX, entre I890 e I9I7, há um esforço dos autores em mostrar as origens da manifestação, construindo a ação de um personagem criador, que fez emergir pelas ruas o princípio de um estranhamento no cotidiano dos bons costumes de uma sociedade carioca e elitizada. Tais crônicas são consideradas pela história como documentos importantes para uma análise do cotidiano do Rio de Janeiro no final do séc. XIX. Tanto Vieira Fazenda quanto Luiz Edmundo descrevem a ação do nosso personagem com detalhes que não estão presentes em outras obras até então, e que são capazes de nos dar dois lados diferentes da criação do personagem em suas descrições.

\section{Teatralidades carnavalescas}

As festas e a ideia de uma "carnavalização do mundo" nos levam a refletir sobre as teatralidades carnavalizadas que estão presentes na diversidade de manifestações do carnaval brasileiro na transição do final do séc. XIX, do Império à República. O carnaval como uma vida expressiva, paralela à cultura oficial, cria outra dimensão, que se opõe aos modos normatizados do cotidiano dos indivíduos inseridos. Estes vivem em paralelo e ambivalentes. Conscientes, são capazes de criar uma linguagem não oficial, em que a palavra, os gestos e as visualidades são livres para parodiar, brincar e ser avessas aos costumes normatizados. $\mathrm{O}$ que chamamos de comportamento teatralizado. A concepção de que o teatro pode ir além das suas limitadas fronteiras foi apresentada também por outro russo, Nicolas Evreinoff (I879-I953). Evreinoff, em I908, no ensaio Apologia da Teatralidade (Apologija Teatral'nosti), destaca o caráter transcendental e apresenta a ideia da teatralidade como parte do instinto do ser humano. Assim, portanto, a cultura se realiza também como uma forma de teatralidade, em que o homem se reconhece: "há elementos de teatralidade em cada aspecto de nossas vidas, em cada rama da nossa atividade" (EVREINOFF, I936 [I908], p. 8I). Evreinoff iria muito além do carnaval, apresentando assim o ato de carnavalizar todo nosso viver. Essa teatralidade do viver seria também ampliada por Roland Barthes (I9I5-I980), que apresentou a teatralidade como tudo além do texto escrito, em que teríamos a teatralidade como um dado da criação.

\footnotetext{
[...] uma espessura de sinais e sensações que é edificada no palco a partir do argumento escrito, é este tipo de percepção ecumênica de artifícios sensuais, gestos, tons, distâncias, substâncias, luzes, que submerge o texto a plenitude de sua linguagem externa. Naturalmente, a teatralidade deve estar presente a partir do primeiro germe escrito de uma obra, é um dado da criação (I97I [I964], p. 37).
}

A teatralidade, assim, seria uma expressão de signos que emergem na relação do olhar do próprio espectador com aquilo que é apresentado. Assim, podemos dizer que a teatralidade se dá no instante, no estranhamento e na captação da verossimilhança, o que causa a identificação e o afastamento entre o movimento ilusório, o imaginário e a realidade. Portanto, a performance, teatralidade em ação, 
é o ato de clivagem (FÉRAL, 20I5). A clivagem, como apresentada por Freud (I940), aponta uma coexistência simultânea e de dois níveis de pensamentos ou realidades contraditórias e que não necessariamente se relacionam. Féral (20I5) apresenta a ideia de teatralidade como uma teorização além dos limites de palco, ultrapassando fronteiras teóricas para ganhar novas configurações. O que Evreinoff apresentou como um instinto, Féral introduz como um expandir teórico do compreender da teatralidade. A autora alerta que a clivagem se dá pelo olhar do outro:

[...] o olhar que lhes dirijo lê certa teatralidade nos corpos que observa, em sua gestualidade, em sua inscrição no espaço. Uma aproximação com o conceito de exotopia de Bakhtin. O simples exercício do olhar inscreve essa teatralidade, colocando a gestualidade do outro no espaço do espetacular. (FÉRAL, 20I5, p. 86)

Silvia Fernandes (2009, p. I7) procura destacar uma diferença entre a performatividade e a teatralidade, afirmando que "enquanto a performatividade é responsável por aquilo que torna uma performance única a cada apresentação, a teatralidade é o que faz reconhecível e significativa dentro de um quadro de referências e códigos", sendo, assim, o instante do "olhar". Parece estranho a performatividade ser o lócus do único e a teatralidade, o lócus do significado, uma interessante distinção, mas que poderia ser contestada: existiria teatralidade sem performatividade? Não aparenta essa discussão agregar uma forma sem conteúdo?

Sem esgarçar o conceito, mas compreendendo seus contextos, podemos dizer que as festas e as manifestações populares carregadas de signos são teatralidades potencializadas que se apresentam como Performances Culturais. Em I955, o antropólogo, filósofo e psicólogo Milton Borah Singer (I9I2-I994), em diálogo com o sociólogo Robert Redfield (I897-I958), estabeleceu pela primeira vez o conceito de Performances Culturais (CAMARGO, 20I3). O conceito foi definido por Singer como "o nome dado a análise de um acontecimento onde "x atuantes" estão em frente a uma determinada plateia, interagindo num tempo determinado" (CAMARGO, 2013, p. 5). Segundo Camargo (2013, p. 20), as performances culturais "se constituem pela identificação, registro e análise de determinado fenômeno em suas múltiplas configurações, em seu processo contraditório de formação, de constituição e de movimento, de estrutura e de gênese, de ser e de vir a ser".

As performances emergem um conjunto de expressões culturais. Nesse sentido, trazemos dois pontos de vista que se estabelecem pela circularidade existente na relação cultural a que estão inseridos. Assim, temos o Zé Pereira como Performances Culturais e as crônicas de Edmundo e Vieira como performances literárias, pois são registros de atos responsivos do escritor perante seus leitores. Richard Bauman (20I4) discute a performance a partir do ponto de vista da linguística. Sua análise considera a fala e os registros que dela se associam como elementos de performance. Tomamos esse contexto como um olhar pormenorizado para as Performances Culturais. A ideia de performance como estranhamento no cotidiano é discutida por Bauman e Briggs (I990) na primeira fase dos seus estudos, na década de I970. Nesse período, os autores, preocupados em estabelecer as questões metodológicas para uma área que emergia nas pesquisas e que se diferenciava dos estudos de ritos, desenvolveram um conceito 
que se tornou uma abordagem nos estudos das performances. Langdon (2007, p. 9), em sua análise sobre a obra de Bauman, destaca que "causar estranhamento, suscitando um olhar não cotidiano, e produzir momentos em que a experiência está em relevo, são características dos atos performáticos”.

Nesse ponto de vista, a performance "é um ato da tomada de posição, isto é, a pessoa que faz a performance, ao invocar o enquadramento da performance, adota uma determinada postura reflexiva" (BAUMAN, 20I4, p. 733) diante do outro. Isso indica que algumas performances, que expressamos em nossa vida, são teatralizadas por emergirem elementos expressivos, que jogam com a ilusão da representação. "Cada comunidade terá seus próprios enquadramentos (frameworks) orientadores metapragmáticos por meio dos quais um indivíduo poderá projetar-se para o público" (BAUMAN, 20I4, p. 733).

Entre as várias abordagens das teorias da performance, a concepção de um evento em suspensão que causa um estranhamento no cotidiano pode ser a que ilumina esta análise, pois, quando pensamos em como o carnaval foi se desenvolvendo no Brasil, é exatamente esse estranhamento popular que fica evidente na literatura carnavalesca. $O$ ápice desta análise é compreender a performance do Zé Pereira como uma ação de estranhamento, considerando a normatização da festa carnavalesca pelos moldes europeus.

A temática do carnaval e suas ressonâncias estiveram presentes nas artes, nos documentos históricos, na literatura, demonstrando que os modos de brincar o carnaval influenciaram a forma como ele era retratado, como veremos na crônica de Luiz Edmundo sobre a passagem do Zé Pereira. Analisar uma pintura ou as crônicas como história das performances insere outros pontos de vista sobre o que já foi executado e dito. Sobre isso, Lopes (1994) problematiza que é possível estudar a performance na história a partir da recuperação de momentos de "alta dramaticidade", como o grito do Ipiranga. $\mathrm{O}$ autor percebe que:

O uso da ideia força de performance nas análises de história da cultura permite um olhar novo sobre certos fenômenos que já foram esquadrinhados através de prismas diversos. Em cada situação histórica concreta, indivíduos e grupos projetam anseios, marcam posições e constroem imagens de si e de seus "outros" e da sociedade envolvente através de formas pelas quais se apresentam e atuam publicamente, dentro de estruturas mais ou menos ritualizadas. O uso de linguagens corporais, técnicas retóricas, expressões faciais, manipulação de emoções, regras de procedimentos coletivos, decoração visual do corpo e do espaço - só para citar alguns elementos performáticos - em manifestações públicas contribuem para a construção de identidades coletivas que ao mesmo tempo refletem e influenciam o curso dos eventos. (LOPES, I994, p.Io).

Esse potencial múltiplo das performances teatralizadas foi observado por Bakhtin (I987 [I965]), em sua perspectiva antropológica, ao analisar que as manifestações no carnaval eram liminares, ambiguidades permeadas pelo riso popular.

A teatralidade carnavalizada em processo, que se relaciona com múltiplos significados e objetos, que age em clivagem do cotidiano e do imaginário, da ficção à alteridade, nos leva ao indivíduo em festa, em um estado liminar onde é possível se 
conhecer e reconhecer como "outro", em seu estado de "não-não-eu" (SCHECHNER, I988, e, mesmo na coletividade, ver o "outro" em estado de alteridade, sentir a vida em outra esfera, parodiando o cotidiano, rindo e criando outros formatos, tensionando e revelando outras configurações. O lugar da performance torna-se cênico, ele é liminar e ambíguo, deixa de ter sua função cotidiana e de origem funcional e passa ser espaço da representação (GOFFMAN, 20I4 [I959]) do eu diante do outro.

O espaço de representação é o lugar do acontecer teatral, compreendendo o teatro na vida como comportamento presente nas relações instintivas do ser humano. Camargo (2008, p. I2) expõe que o teatro é o lugar do acontecimento das ambiguidades,

[...] onde as coisas retêm mais de um sentido, seu nome já define esse processo. $\mathrm{O}$ vocábulo grego théatron estabelece o local físico do espectador, "lugar aonde se vai para ver” e onde, simultaneamente, acontece o drama completo visto, real e imaginário. O representado no palco é imaginado de outra(s) forma(s) pela plateia. A audiência vê o que não quer ver e finge não ver o que se vê. Os atores e sua equipe trabalham para produzir a ilusão do que não é mostrado. Algumas vezes, com certa culpa, tenta-se dizer que a ilusão é uma ilusão, uma cegueira cultural consentida.

A complexidade da ideia de teatralidade se abre para entender o ato de ilusão no palco no cotidiano. Podemos estabelecer esse instante do observado e do observador: "o teatro é um fenômeno que existe realmente nos espaços, do presente e do imaginário, e nos tempos coletivos, individuais e históricos que formam a partir desses espaços." (CAMARGO, 2008, p. 2). As teatralidades carnavalizadas, com suas performances cotidianas e em momentos marcados como as festas, os rituais, as ações políticas e/ou artísticas, podem ser analisadas e recuperadas para se refletir sobre sua trajetória ou sobre o olhar de quem contou aquela história em forma de texto, imagens e documentos.

Desde os tempos das cartas de Pero Vaz de Caminha, os textos informativos no Brasil já delineavam suas polifonias: havia, desde os relatos das novas terras e as percepções das experiências, um tom memorialista (COSTA, 2005), que marcou por um período a característica do desenho estrutural que deveria seguir esse tipo de texto. Mas as publicações em folhetins recriaram as formas de se pensarem as crônicas apenas como memórias literárias: os textos tornaram-se abordagens de assuntos sérios com tons de humor, como forma de se aproximar do leitor. A crônica tem como essência a ambiguidade. Cristiane Costa, em seu livro Pena de aluguel (2005), destaca que pode ser considerado autônomo um tipo de literatura que tem como característica a ambiguidade entre o conto, a reportagem, o ensaio, o humorismo e até o poema em prosa; a crônica se delineia como o gênero que transita entre o relato e a análise da vida social, do meio que se vive, e os traços do jornalismo.

Compreender a crônica como um documento importante para este estudo tem como base entender o lugar de fala dos cronistas e, consequentemente, como seus relatos vão desenhar um símbolo do carnaval, na tentativa de homogeneizar as manifestações carnavalescas na virada do século XIX. Sobre esse tema, Cunha (2002) reuniu alguns ensaios sobre a história social da cultura, desenvolvendo um estudo sobre as frestas deixadas pelas análises do carnaval. Entre esses ensaios, a 
pesquisadora publica uma análise intitulada: “Vários zés, um sobrenome: as muitas faces do senhor Pereira no carnaval carioca da virada do século” (p. 37I-4I7, 2002). A pesquisa é resultado de um estudo da historiografia social estruturando como o Zé Pereira se torna uma figura central do carnaval carioca. A autora analisa vários documentos que de alguma forma mencionam o Zé Pereira para contrapor os aspectos de quem fala, de onde fala e por que fala.

Antes de prosseguir, vejamos o que nos dizem nossos autores cronistas sobre a aparição desse personagem em terras cariocas:

[...] rigores, comunicados de pais a filhos, explicam satisfatoriamente o fato da preferência, que os nossos antepassados davam sempre ao entrudo, mais ou menos tolerado pelas autoridades, desde que não fossem causa de desordens, desacatos e crimes. Isto esclarece a relutância em ter aceito o Carnaval, que por fim venceu, depois de aturada propaganda. Se os primeiros bailes carnavalescos se realizaram em I846, nem por isso cessou ele todo o entrudo. Com o aparecimento (I854) das duas primeiras sociedades - Sumidades Carnavalesca e Veneziana - obtiveram-se os primeiros triunfos, completados depois pelos imponentes e grandiosos préstitos, que tornaram durante certo período, afamado o Carnaval do Rio-de-Janeiro.

$\mathrm{O}$ que em relação às classes elevadas fizeram os propagandistas contra o entrudo, realizou-o quanto à arraia miúda modesto artista sapateiro, pacato burguês, introduzindo o chamado Zé-Pereira, verdadeiro derivativo, que hoje goza entre nós do privilégio de senhor de baraço e cutelo.

Carão amorenado e simpático, olhos brejeiros, bigode curto e grisalho, cabelo todo branco e à escovinha, barba escanhoada, altura regular, ombro e cadeiras largas, peito cabeludo, musculatura de atleta, sempre em mangas de camisa, calça de brim pardo apertada ao amplo abdome por estreita correia, negação ao suspensório, chinelos de liga, vendendo saúde, sadio e robusto sem nunca ter tomado um remédio - eis em rápidos traços o retrato do patriarca do nosso Zé-Pereira, o conhecido e inolvidável José Nogueira de Azevedo Paredes.

Miguelista intransigente, andou nas bernardas da Maria-da-Fonte e da Patuléia; era, contudo, amigo do filho do Pedro (o imperador) e de todos os Brasileiros. Acidentes da vida, que não vêm ao caso, fizeram Nogueira procurar o Rio-de-Janeiro, onde, à rua de São José n. 22, abriu modesta oficina de sapateiro. Essa casa, hoje completamente reformada, era constituída por baixo e feio sobradinho de grades de pau, onde também por muito tempo habitou a conhecida parteira Luiza velha, de dentada, feia, rosto de pergaminho engelhado - uma carcaça.

Foi ali que, em uma segunda-feira de Carnaval, Nogueira, em amistosa palestra com alguns patrícios, recordando-se das romarias, das esturdias e estrondos do Ubi Natal resolveu de súbito com eles sair à rua e ao som de zabumba e tambores, alugados às pressas, dar uma passeata pela rua da cidade. Sucesso inaudito; quando ao amanhecer já meio na chuva, regressou aos lares, esse triunvirato de folióes podia exclamar como Cesar - veni, vidi, vinci!

No ano seguinte, apareceram os imitadores, mas nenhum deles levou de vencida o primacial Zé-Pereira do Paredes, que se distinguia ao longe pela certeza das pancadas 
no bombo e pelo ritmo dos tambores. Esse segredo levou-o ele para o túmulo, nunca sendo excedido nem jamais imitado.

Quanto à origem do nome dizem uns que, em certas localidades de Portugal, é o bombo conhecido por Zé-Pereira; querem outros, e isto é mais provável: na primeira noitada de bom sucesso os companheiros do Paredes, na força do entusiasmo e influenciados pela vinhaça, trocavam o nome do chefe e davam vivas ao Zé-Pereira, em vez de Zé-Nogueira.

Ele e os sócios compravam bombo e tambores, que depois do Carnaval eram com cuidado guardados em capas de metim no fundo da loja. Todos os domingos, como o d. Martinho do D. Jayme, Nogueira revistava os instrumentos para ver se ratos e baratas tinham danificado os seus queridos amigos.

Passando-se da rua de São-José para a do Cotovelo n. 38, continuaram sucessivamente os triunfos e sucessos do barulhento Zé Pereira; foi este até adotado pelas sociedades carnavalescas e teve entrada nos salões dos Tenentes, Fenianos, Democráticos, etc.

Sagrado pelos simpáticos populares, foi Paredes proclamado o primus inter pares e venerado por amigos, discípulos e entusiastas como o pontífice da pândega e do sarilho. Não se ensoberbeceu com isso e atribuía o mérito à natureza que lhe dera embocadura. (FAZENDA, 20II, p. 327-328).

O texto de Vieira Fazenda (I874-I9I7) é típico de um autor que transitava entre o memorialismo e o tom das crônicas. Falecido aos 43 anos, seus mais de 500 artigos foram publicados em algumas revistas da época, e em I9I9 reunidos na Revista de Instituto Histórico e Geográfico Brasileiro (IHGB), depois reeditada, em I940. O olhar de Vieira sobre o cotidiano no Rio de Janeiro demonstra a tentativa de apresentar o personagem Zé Pereira e a sua relação harmoniosa com os festejos carnavalescos. Sobre essa obra, Cunha (2002) destaca nas notas de sua pesquisa que, "como a maior parte das narrativas de folcloristas, não há indicação de fontes que permitam confrontar a narrativa com outras referências, de modo que ela é a única de si mesma” (p. 4I3).

Vieira Fazenda formou-se em belas letras e medicina, era bibliotecário do IHGB e escritor. O artigo escrito em I904 apresenta sua proximidade do personagem Zé Pereira. No relato, José Nogueira de Azevedo Paredes é apresentado como membro de uma sociedade festiva. Há no trecho um discurso evidente ao demonstrar como os grupos brincavam o entrudo, uma antiga forma de se divertir no carnaval carioca, bem como a afeição de Vieira pelo Zé Pereira, como um divertimento popular. Na tentativa de demonstrar que essa nova brincadeira poderia substituir o antigo entrudo, Vieira Fazenda indica traços da origem do personagem, realçando características para a demonstração de sua origem luso-brasileira: I. Carão amorenado e simpático; 2 . Miguelista - Partidário ou simpatizante do miguelismo. Miguelista é o nome dado na historiografia portuguesa aos apoiantes do chamado Miguelismo, nomeadamente os que lutaram pela legitimidade permanente do ex-infante D. Miguel de Bragança na linha de sucessão ao trono português e que vieram depois a fundar o Partido Legitimista e o Partido Realista que nele se integrou; 3. Andou nas bernardas da Maria-da-Fonte e Patuléia - Revolta do Minho, é o nome dado a uma revolta popular ocorrida na primavera de 1846 contra o governo cartista presidido por António 
Bernardo da Costa Cabral em Portugal. A revolta resultou das tensões sociais remanescentes das guerras liberais, exacerbadas pelo grande descontentamento popular gerado pelas novas leis de recrutamento militar que se lhe seguiram, por alterações fiscais e pela proibição de realizar enterros dentro de igrejas; 4. Ubi Natal - Festas de Natal ao som de bombos em Portugal.

Para demonstrar o contato com o personagem vivo e contextualizar seu pioneirismo brasileiro, demonstrando sua influência portuguesa, Vieira Fazenda (20II) constrói seu relato trazendo detalhes dos últimos dias de José Nogueira e reivindica seu trono de criador do popular Zé Pereira. Para dar veracidade aos fatos, destaca as conversas que teve com José Nogueira e indica o local onde o amigo foi enterrado.

Homem de bem às direitas, nunca faltou aos seus deveres, e os folguedos carnavalescos jamais o tiraram da linha reta da probidade e da honra. Desgosto teve-os em grande quantidade; mas sua alma varonil nunca se quebrantou - pesares, dizia, não adubam sopas. Jovial e pilhérico, contava com chiste anedota de sua mocidade, do tempo ele Junot de d. João VI e das lutas de d. Pedro e d Miguel. Trabalhou sempre até que, vítima de um insulto apoplético, faleceu em vésperas de um Carnaval, em que ainda queria mostrar quanto valia. Foi sepultado, segundo é fama, no cemitério do Cajú; mas antigos amigos e conhecidos ignoram o paradeiro dos despojos mortais do velho Nogueira Paredes, que conheci de perto e com quem, às vezes, conversei. Está feita a reivindicação. Ao Nogueira ninguém ousará disputar a glória da descoberta do Zé-Pereira. E, se lá no etéreo assento onde habitas, memória desta vida se consente, recebe, no dia de hoje, esta singular lembrança, já que os continuadores da tua obra retumbante não se lembram de ti e nem sabem o teu nome. O mundo foi, é, e será sempre assim. (20II, p. 329)

Diferentemente de Vieira Fazenda, que demonstrava ter proximidade com José Nogueira, Luís Edmundo (I880-I96I), em sua obra O Rio de Janeiro do meu tempo, publicada em 1938 (reedição em 2003), retrata uma sociedade em processo de construção em busca de uma identidade brasileira. Se na obra de Vieira Fazenda havia uma tentativa de mostrar as relações alegres e harmoniosas, para identificar uma origem portuguesa, nos escritos de Luís Edmundo há demonstração do que precisava ser higienizado para que o Rio de Janeiro adentrasse a modernidade dos europeus. Considerado jornalista e historiador, amante da política do prefeito Francisco Pereira Passos (I902-I906) na virada do século XIX para o XX, sua obra é influenciada por um espírito de mudança dos padrões que não admitia a ideia de "festa da rua" como algo civilizado.

CARNAVAL foi sempre, entre nós, uma festa de plebe. E de rua. Zabumba das Pandeiradas, Gaitadas, Gritos: vi-vôô! Berrarias:

Evoééé! Desafogo grosseiro da massa. Ventura desalinhada de almas impetuosas e rudes. Alegria tresloucada e pagã. Em 1852, para aumentar tanta balbúrdia, como um fantasma, surge o neurastenizante zé-pereira! 
Sete ou oito maganos vigorosos, tendo por sobre os ventres empinados satânicos tambores, caixas de rufo ou bombos, por entre alucinantes brados, passam pelas ruas, batendo, surrando, martelando, com estrondo e fúria, a retesada pele daqueles roucos e atroadores instrumentos. É um desabafo estúpido e brutal de criatura que sente a necessidade de cantar, debater, de bramir a alegria em cachões, que lhe vai n'alma. Que, se o homem de elite, quando venturoso, sorri, o da plebe, em geral, feliz, expande-se em ruídos, gargalha, espinoteia e dá patadas.

A princípio, o zé-pereira é um préstito de fragoroso alarido. Batecum Estrondear de pelicas. Berraria caótica e hiperacústica de sons loucos, de brados, loucos, de barulheira louca. Não se canta. De resto, as palavras não se riam ou vidas, ante o ensurdecedor e reboante conflito de estrondos e retumbos que a fúria de braços vigorosos arranca, vi o lentamente, ao oco das caixas, dos bombos e tambores

Dig, Dig, Dig, Bum.

Dig, Bum,

Dig, Bum,

Dig, Dig, Dig, Bum.

Dig, Bum,

Bum, Bum.

Só quando aqui nos chega a mar chabuliçosa dos Pompiers de Nanterre, que o povo carioca barulha e o assobio de mole que pela rua desafina e consagra, é que se consegue um pouco de armistício para o ouvido do próximo. Habeas corpus feliz. Trégua amável. Não há rancho carnavalesco que não cante.

E viva o zé-pereira

Que a ninguém faz mal,

E viva a bebedeira

Dois dias de Carnaval!

Ta, tara-ra-ra

Ta, tara-ra-ra

Ta, ta-ta-ta-ta.

Logo, porém, recomeça o tã-tã cavernoso das pelicas em sova, enquanto a massa estouvada e bulhenta ondula, rola em fúria acesa pelas ruas estreitas da cidade, como uma roda de fogo movida por Satã.

É o negro. É o branco. É o mulato. É o Brasil. É toda a nacionalidade borbulhando, estorcendo-se, saltando, bocas em os. Faces híla respingando suor ou zarcão. Trejeitos. Saracoteios, Chufas, Guinchos.

Loucura geral. A rua coalha-se de doidos. Os que têm juízo, fogem... Os irracionais, habituados ao homem melancólico, rosnam e, desconfiados, olham-no de soslaio. E continua a multidão aos boléus, pelas ruas, sanhuda e desenfreada, na sua infatigável barulheira, sem sede ter, sem diminuir, sem afrouxar aquela nervosidade que a todos desnorteia.

Há quem desame a rajada terríssona e iracunda, capaz até de romper os tímpanos do ouvido, matina da formidolosa que os sentidos contundentes perturbam e exasperam, mas há também quem com ela se encante e se embriague, sorvendo-a como quem sorve canjirões de vinho. A mais perigosa de todas as bebedeiras é a que põe dentro do 
coração de um homem triste o favo da alegria e do prazer. Chega a matar. Que há quem morra de contentamento, como quem morra de dor.

O zé-pereira é português. Sente-se. Na alegria desabusada que desperta, no ruído infernal que precipita. Achou, aqui, clima propício. Ficou. Faz bem na terra onde a alegria é pouca; reconforta, estimula, atiça, alenta, anima. Quem tiver ouvidos de tímpano fino ou delicado que os tape ou fuja. Que a alma rude do homem que trabalha e sofre o ano inteiro precisa expandir-se em grosseiras e reais alegrias:

Dig, dig, dig, bum.

Dig, bum.

Dig, bum.

Trouxe às plagas da América o pavoroso ruído, certo José de Azevedo Paredes, que pelo nome não se perca. Era um rapaz filho do Porto, simpático e brincalhão, com loja de sapateiro, ali à Rua de São José. Parece que a ideia de zabumbar nasceu-lhe do hábito de bater solas. E Paredes, dizem que as sabia bater como bem poucos. Questão de pulso. Vigor. Ritmo. Na hora de despedir o peso da vaqueta era como se vibrasse o martelo dos couros. Zabumbava. E zabumbando, zabumbava tanto que estourava e partia bombos e tambores.

Um arrebenta-pelicas de primeira! Foi grande sucesso a novidade, logo que apareceu. Depois, delírio. Acabou desespero. Aflição. (EDMUNDO, 2003 [I938], p. 46I-478).

Em seu texto, Luís Edmundo se utiliza da liberdade, própria da crônica, para fazer com que seus leitores compreendam a experiência "infernal" que eram as saídas dos “zé-pereira”, em um discurso bem elaborado para demonstrar a necessidade de se conterem tais atividades em defesa de novos costumes. $\mathrm{O}$ autor argumenta as origens de nosso personagem, criador da manifestação, enfatizando que a questão foi deixar os imitadores para continuarem a balbúrdia, como o próprio diz. Cunha (2002), em suas notas, nos lembra que a obra de Edmundo foi escrita quando ele tinha 60 anos: ele nasceu em I878 (e morreu em I96I), sendo uma constatação que nos leva ao desígnio de um relato que já se distanciava dos traços de origem do próprio José Nogueira levantados por ele.

\section{Zé Pereira carnavalizado}

A transição do personagem nos mostra como a inversão do grotesco está presente, se notarmos que o José Nogueira é retratado como:

Carão amorenado e simpático, olhos brejeiros, bigode curto e grisalho, cabelo todo branco e à escovinha, barba escanhoada, altura regular, ombro e cadeiras largas, peito cabeludo, musculatura de atleta, sempre em mangas de camisa, calça de brim pardo apertada ao amplo abdome por estreita correia, negação ao suspensório, chinelos de liga, vendendo saúde, sadio e robusto sem nunca ter tomado um remédio. (FAZENDA, I9I9, p. 327)

Era um rapaz filho do Porto, simpático e brincalhão, com loja de sapateiro, ali à Rua de São José. (EDMUNDO, 2003 [I938], p. 477) 
Nota-se um personagem avesso ao retratado pela revista Fon Fon na figura I, que apresenta os traços exagerados que satirizam o bater dos bombos em movimentos pesados. O "rapaz filho do porto" adequa-se aos modos dos bons costumes da elite carioca, com bom comportamento, com traços do estereótipo português e que se encaixa na forma que nossos cronistas querem idealizar para o novo brasileiro, viril e masculinizado. A versão da masculinidade viril percorre os escritos em que as descrições detalham o homem forte, o brasileiro simpático e alegre. Essa masculinidade, tomada como característica, reflete o contraponto com a menção da participação das mulheres na brincadeira carnavalesca, o que é, até certo ponto, inexistente, sendo elas excluídas do divertimento. Vejam que apesar de Vieira Fazenda trazer uma concepção da performance como algo romantizado, a compreensão de grotesco presente na carnavalização está associada à dimensão da rua. Quando a ação performática ganha as ruas cariocas, ela deixa de ser um retrato civilizado, na concepção de Luís Edmundo, e se transforma na ingratidão dos “imitadores”, que não reconhecem seu criador, e nos loucos, doidos e alucinados.

No ano seguinte, apareceram os imitadores, mas nenhum deles levou de vencida o primacial Zé-Pereira do Paredes, que se distinguia ao longe pela certeza das pancadas no bombo e pelo ritmo dos tambores. Esse segredo levou-o ele para o túmulo, nunca sendo excedido nem jamais imitado. (FAZENDA,I9I9, p. 328)

Sete ou oito maganos vigorosos, tendo por sobre os ventres empinados satânicos tambores, caixas de rufo ou bombos, por entre alucinantes brados, passam pelas ruas, batendo, surrando, martelando, com estrondo e fúria, a retesada pele daqueles roucos e atroadores instrumentos (...) Loucura geral. A rua coalha-se de doidos. (EDMUNDO, 2003 [I938], p. 475-478)

No estudo da linguagem, Bakhtin caracteriza como dialógicos todos os tipos de discursos, e essas construções se dão em enunciados entre textos e contextos (JUNIOR, 2005). Ao analisar os discursos produzidos por nossos cronistas, podemos estabelecer as relações dialógicas entre a constituição da linguagem e a sociedade composta naquele momento. Assim a visão dos nossos interlocutores e suas polifonias podem ser acessadas no processo de leitura, gerando imagens performáticas e, consequentemente, teatralizadas. Vejam que há intenção de que o leitor tenha a capacidade de criar uma imagem do personagem por meio da leitura, provocando uma atitude responsiva.

Em tempos em que a elite precisava de um elemento para combater a versão de um carnaval popular e forçar a introdução de um novo tipo, o personagem Zé Pereira não poderia ser uma figura estereotipada do meio popular ou das ruas, mas alguém com prestígio e parecido com uma versão europeia, sendo, inclusive, português, segundo a descrição de Vieira Fazenda. A teatralidade na construção e na descrição deste "homem de bem" não se abala nem quando é acrescida dos instrumentos de percussão, que eram os objetos importantes para a performance que percorria as ruas, condenados por Luís Edmundo por causa da "barulheira” emitida. 
A oscilação entre a disposição de incorporar símbolos coletivos nascidos da alegre "alma” popular e a rejeição radical de algumas de suas dimensões frequentou muito cedo as pautas das elites e dos "homens de letras" preocupados em desenhar uma identidade para a nação. Em meio à ambiguidade política que sempre cercou uma noção como esta, o zé-pereira prestava-se à positivação por outro bom motivo: em anos de aguda tensão racial e social em torno da causa da abolição que se avultava, ele parecia ter uma origem menos comprometedora que os temidos batuques africanos. (CUNHA, 2002, p. 376).

A virada do séc. XIX é marcada por essa necessidade de se criar uma ideia de nacionalidade. Como podemos perceber até então, nossos autores criaram recursos linguísticos e performáticos, em seus discursos para o leitor. Veja como o grotesco é detalhado na descrição dos seguidores do Zé Pereira, em algumas passagens da crônica de Luís Edmundo (2003 [I938], p. 475-476):

Sete ou oito maganos vigorosos, tendo por sobre os ventres empinados satânicos tambores

Logo, porém, recomeça o tã-tã cavernoso das pelicas em sova, enquanto a massa estouvada e bulhenta ondula, rola em fúria acesa pelas ruas estreitas da cidade, como uma roda de fogo movida por Satã.

O uso de termos como "satânicos tambores", "cavernoso" e "roda de fogo movida por Satã” exprime o rebaixamento da performance. Expressões que criam o contraponto com a religiosidade, determinando que as transformações ocorridas desde a origem tornaram-se ações consideradas não civilizadas para a sociedade carioca. Assim "a característica determinante do realismo grotesco é o rebaixamento de tudo que é elevado e espiritual, ideal e abstrato, a um nível material e corporal, sublinhado como baixo" (HERMENEGILDO, I995, p. I4).

A linguagem atribuída às teatralidades do Zé Pereira pode ser analisada nos enunciados dos autores na demonstração de pequenas ações. A segunda vida do povo carnavalesco - a festa, o riso, a linguagem - se diferencia do cotidiano. Essa nova linguagem que se forma se estabelece por uma construção textual que, carnavalizada, reflete a ação performática evidenciada na bebedeira, na grosseria, na alegria e nos gritos expandidos, bem como nas onomatopeias da reprodução fonética dos bumbos, presentes na obra de Edmundo (2003 [I938], p.46I-478) como: "A mais perigosa de todas as bebedeiras é a que põe dentro do coração de um homem triste o favo da alegria e do prazer"; "Que a alma rude do homem que trabalha e sofre o ano inteiro precisa expandir-se em grosseiras e reais alegrias"; "vi-vôô Evoééé”; "Dig, Dig, Dig, Bum. Dig, Bum” e "Ta, tara-ra-ra”.

As crônicas, ao estabelecerem a construção do personagem Zé Pereira, utilizam-se de recursos teatralizados e carnavalizados para contrapor ou impor uma nacionalidade civilizada nos moldes europeus. Dessa forma, iremos perceber, por meio de seus discursos, que "a carnavalização não é um esquema externo e estático que se sobrepõe a um conteúdo acabado, mas uma forma insolitamente flexível de visão artística, uma espécie de princípio heurístico que permite descobrir o novo 
e inédito." (BAKHTIN, 20I5 [I963], p. I68). Os autores criam um mundo utópico e carnavalesco. Essa festividade está marcada pela sensibilidade das memórias, que buscam evidenciar uma sociedade diferente de seu tempo, em que a festa carnavalesca estava marcada pelo conflito de grupos, por diversas mudanças territoriais e pelas marcas deixadas pela escravidão no Brasil. Enquanto os homens de letras forçavam para se afirmar, os grupos sociais lutavam para se reestabelecer na nova estrutura de uma sociedade sem escravos.

Cunha (2002), em sua pesquisa sobre os vários Zés, destaca que não é possível estabelecer uma gênese devido às polifonias presentes nos discursos, nos documentos e nas imagens. As transformações ocorridas nas performances nos dizem que o Zé Pereira ganhou vários espaços, desde as ruas até os salões das grandes sociedades, sendo incorporado e até confundido com outras manifestações do carnaval carioca entre sociedades carnavalescas, cordões e ranchos. Um exemplo dessas expressões é a cena cômica O Zé-Pereira Carnavalesco (I869)5, escrita e encenada pelo ator Francisco Corrêa Vasques (I839-I892). Trata-se de uma paródia da peça francesa Les pompiers de Nanterre que levou aos palcos os elementos da rua carnavalesca, transformando a manifestação da rua e suas pluralidades. A cena que incluía diálogos e canções trazia um verso repetido que foi amplamente divulgado entre as sociedades carnavalescas do final do séc. XIX no Rio de Janeiro. "A cançoneta, que se tornou amplamente conhecida até os dias de hoje, foi levada aos palcos com uma nova letra, preparada especialmente para a ocasião" (FERREIRA, I979 [I939], p. 40I):

\author{
Viva o Zé Pereira \\ Que a ninguém faz mal, \\ E viva a bebedeira \\ Nos dias de carnaval. \\ Zim, balala! Zim, balala! \\ E viva o carnaval!
}

A carnavalização da cançoneta parodiada e elevada nos versos "E viva a bebedeira" e "Zim, balala! Zim balala" nos traz uma linguagem da rua, em prol de uma comunicação dialógica com o leitor, tendo em vista a concepção de um enunciado em que os signos presentes nas onomatopeias e na bebedeira de carnaval são entendidos diretamente por seus aspectos sociais, culturais e históricos (BAKHTIN, I929) fazendo circular um discurso concreto que cria a ideia de um Zé Pereira unificado e nacionalista e que pode agregar as pessoas em uma só canção.

5 A peça possui elementos importantes de carnavalização em seus personagens, exatamente para construir uma visão de "pacificidade e convivência entre os personagens e plateia" (CUNHA, 2002, p. 377). Portanto, essa análise não caberia neste trabalho, pois evoca elementos do teatro ligeiro no final do Séc. XIX e toda a trajetória de Francisco Correia Vasques, um dos percursores desse estilo no Brasil. 


\section{Zé Pereira e suas novas expressões}

As performances são comportamentos. Conforme nos apresenta SCHECHNER (2005), toda performance é formada por frames, tiras de comportamentos que estão em constante restauração. Por isso não poderíamos deixar de destacar que a ideia de uma unificação nacional e pacífica, desenvolvida por nossos cronistas da virada séc. XIX e utilizada como missão para a construção de uma identidade brasileira, apenas se recriou, não atingindo seu objetivo homogeneizador. Ao compararmos o retrato descrito do Zé Pereira, desenhado por Vieira Fazenda e Luís Edmundo, que elencaram a alegria, mas condenaram a festa do povo, vamos perceber que o povo resiste e se reconstrói em comportamentos restaurados de décadas em décadas.

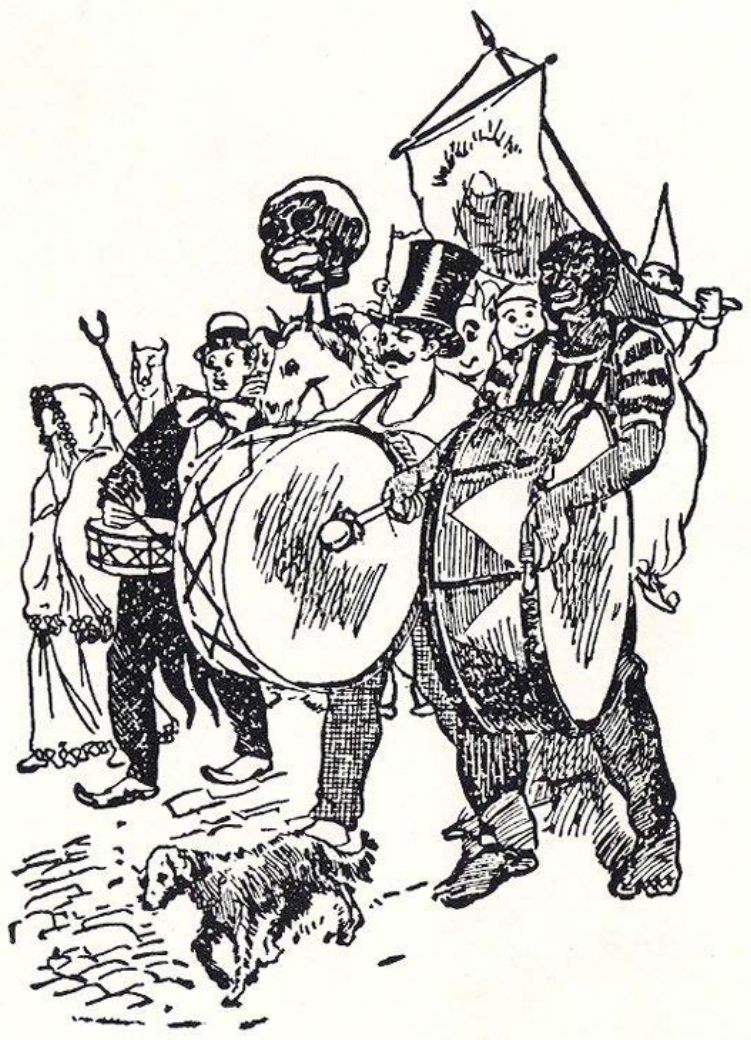

Figura 2 - Zé-pereira - Desenho de Armando Pacheco. Fonte:

PACHECO, I957 in EDMUNDO, I957, p. 478.

O Zé Pereira na imagem de Armando Pacheco (I9I3-I965), que compõe o livro de Luís Edmundo, retrata uma mistura de personagens carnavalescos. Os bumbos que vêm à frente, seguidos do estandarte, dos mascarados e dos fantasiados. Elementos que eram atribuídos a outras manifestações também estão presentes, como os diabinhos e as caveiras, que eram característicos nos cordões carnavalescos (CUNHA, 2002; FERREIRA, 2004). 


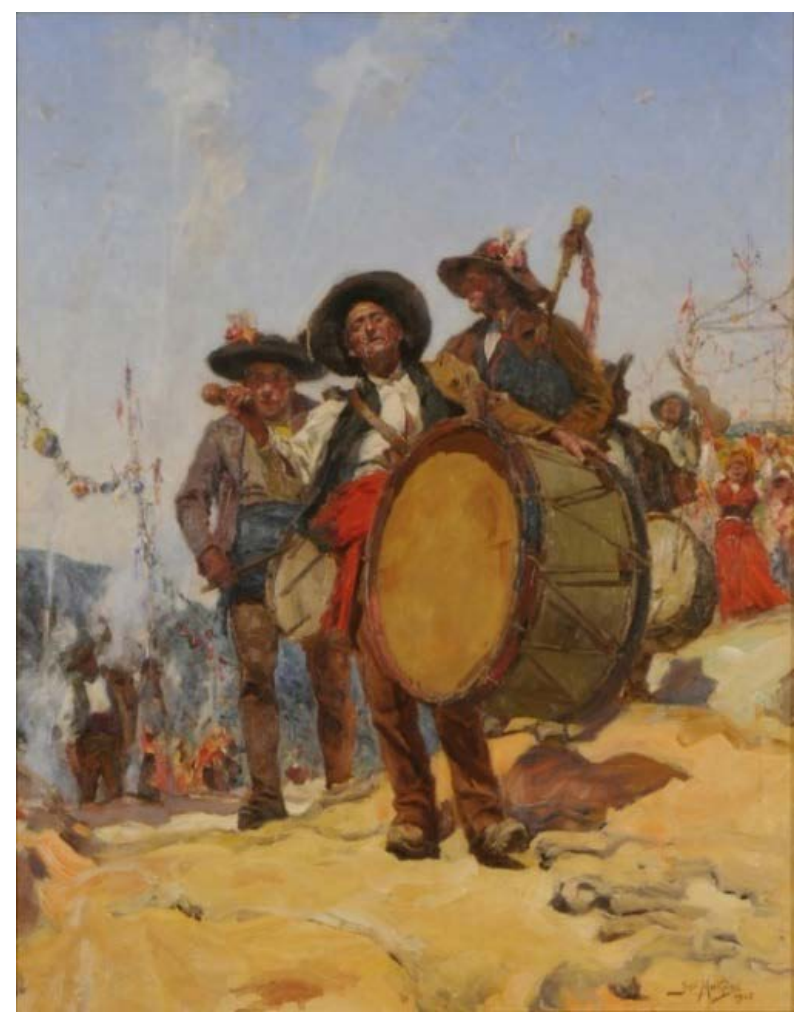

Figura 3 - José Malhoa. Volta da feira (Chegada do Zé Pereira à Romaria). Óleo sobre tela, I905. Fonte: Arquivo digital ${ }^{6}$.

Observamos que a figura 3 é uma pintura portuguesa de I905, e que os elementos e a disposição dos personagens, em ambas as figuras, estão com a mesma distribuição espacial, atestando a relação dos contextos brasileiros em relação ao português. Nos dias de hoje, os bombos portugueses, assim como os brasileiros, tornaram-se teatralidades diversas, demonstrando o que Cunha (2002) intitula de vários Zés. Vejamos as imagens a seguir:

6 Disponível em: https://br.pinterest.com/pin/502855II4639266I3I/?lp=true. Acesso em: nov. 2019. 


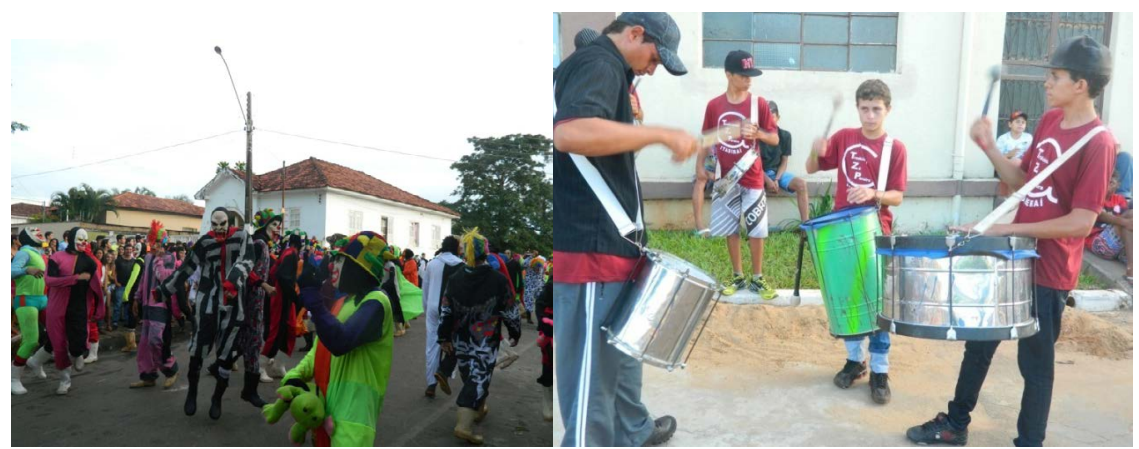

Figuras 4 e 5 - Zé Pereira em Itaberaí-GO. Fonte: FARIA, 20I4. Acervo Etnográfico

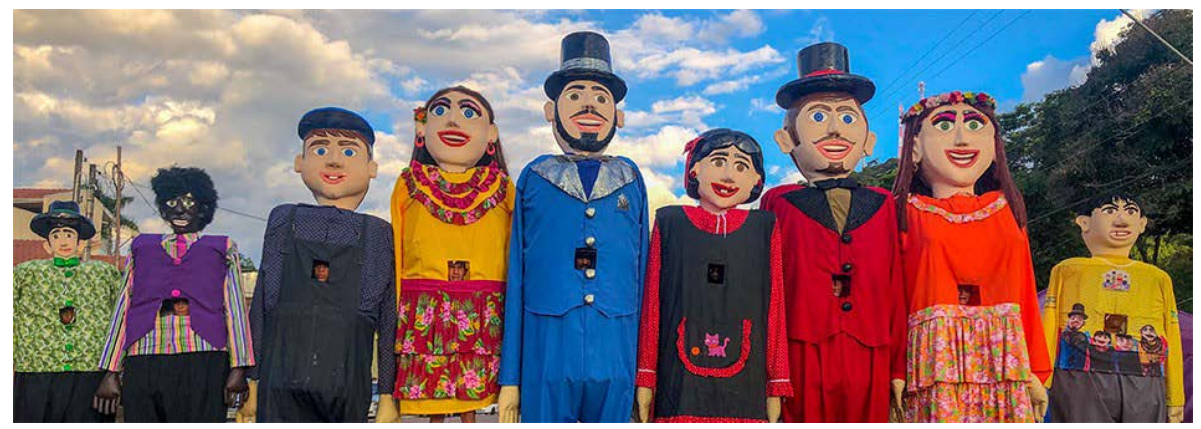

Figura 6 - Bloco do Zé Pereira em São Bento do Sapucaí-SP. Fonte: Arquivo do grupo.

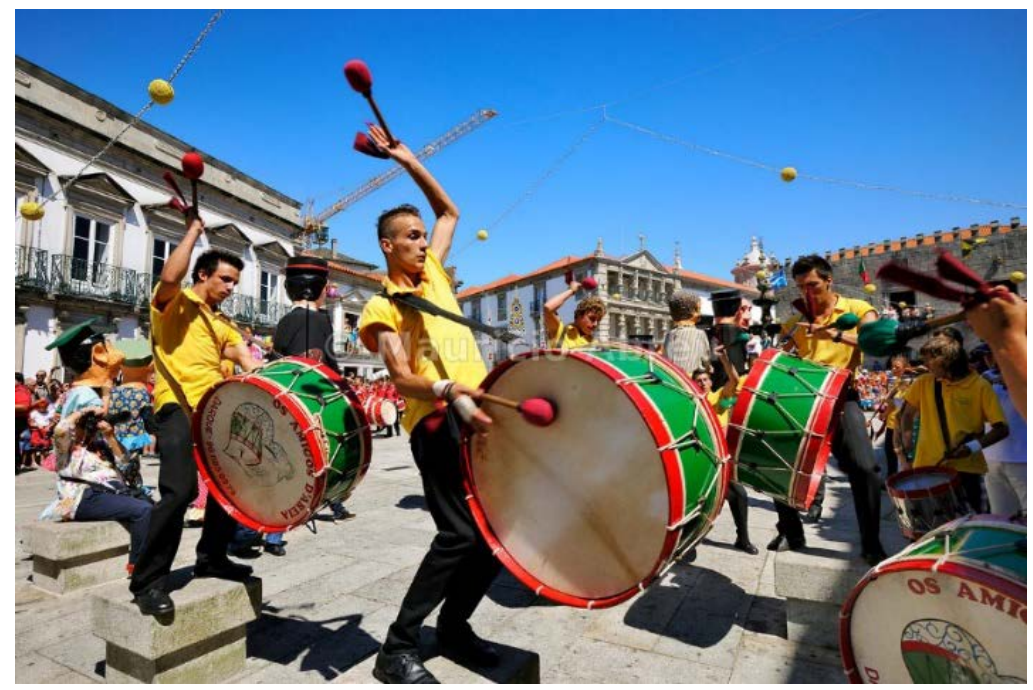

Figura 7 - Zé Pereira de Portugal. Fonte: Arquivo digital.7

7 Disponível em: http://www.imagesofportugal.net/media/8d5863fc-II5a-IIe3-95ed-d38896f35Ie5-traditionaldrummers-zes-pereiras-acting-during-the-our-lady \} 
Bakhtin (I987 [I965], p. I62-I63) percebe que "a composição e o caráter dos elementos capazes de metamorfosear o conjunto da linguagem e de criar um grupo de pessoas que utilize uma expressão familiar modificam-se no curso dos tempos". Essa característica significante da carnavalização nos mostra que as imagens anteriores e suas composições estéticas tornaram-se modificações valorosas que definem cada grupo e seus indivíduos. A teatralidade emergente na estética das cores, dos instrumentos, das vestimentas, das máscaras e da gestualidade nos corpos alterados, nos mostra que as características no interior dos grupos com suas linguagens próprias, se fortaleceu e conduziu para o surgimento de uma diversidade de performances brasileiras e portuguesas.

\section{Considerações finais}

A teatralidade carnavalesca presente nas manifestações culturais dos grupos que se intitulam Zé Pereira nos dias de hoje nos faz refletir sobre o processo de constituição dos grupos e como suas especificidades os fazem construir uma nova linguagem verbal e corporal. O uso dessa linguagem que surge no interior dos grupos carnavalescos influenciou e influencia as formas constituintes de comunicação de várias épocas: isso aconteceu na Idade Média, na forma como a igreja estabeleceu se comunicar com seus fiéis e foi incorporando a festa ou na tensão de tentar modificar, a seu modo, adaptando seu calendário; ocorreu no Renascimento, por meio das artes; e no Brasil, por meio das charges, das paródias, da música, do teatro ligeiro, do teatro de revista, da poesia e de tantas outras formas de discurso.

A teatralidade permeada pelo riso, na tensão do limiar, do grotesco, que nos dá vários zés, em variados carnavais, nos mostra que o jogo coletivo, com suas próprias regras e sua capacidade híbrida, vai contra a tentativa de homogeneizar as festas. O que nos aponta que o Zé Pereira foi lido em épocas e lugares diferentes e se destaca pela capacidade de se adaptar ao contexto em que está ativo.

SOBRE OS AUTORES

MARCELO FECUNDE DE FARIA é doutorando em Performances Culturais (PPGPIC/UFG). Grupo de Pesquisa Máskara - Núcleo Transdisciplinar de Pesquisas em Teatro, Dança e Performance (UFG). Academia Edu: https://independent.academia.edu/ MarceloFecunde. Núcleo de visibilidades de pesquisas em Performances Culturais: @performances. culturais

fecunde@gmail.com

https://orcid.org/0000-0002-0562-5259. 
ROBSON CORRÊA DE CAMARGO é doutor em teatro (ECA/USP). Idealizador e fundador do Programa de Pós-graduação em Performances Culturais da UFG (20II, Mestrado e Doutorado). Encenador e crítico de teatro, coordena a Rede Goiana de Pesquisa em Performances Culturais e o Máskara - Núcleo Transdisciplinar de Pesquisas em Teatro, Dança e Performance (UFG).

Artigos em: https://www.researchgate.net/profile/

Robson_Camargo/research

robson.correa.camargo@gmail.com

https://orcid.org/oooo-0o03-3740-4722

\section{REFERÊNCIAS}

ARAÚJO, Hiram. Carnaval: seis milênios de história. Rio de Janeiro: Griphus, 2000.

BAKHTIN, M. A cultura popular na Idade Média e no Renascimento: o contexto de François Rabelais. Tradução de Yara Frateschi Vieira. São Paulo: Hucitec, I987 [I965].

BAKHTIN, M. Para uma filosofia do ato responsável. Tradução de Valdemir Miotello e Carlos Alberto Faraco. São Carlos: Pedro e João Editores, 20Io [I920-24].

BAKHTIN, M. “Arte e responsabilidade”. In: BAKHTIN, M. Estética da criação verbal. 6. ed. Tradução de Paulo Bezerra. São Paulo: Martins Fontes, 20пra, p. XXXIII-XXXIV.

BAKHTIN, M. “O autor e a personagem na atividade estética”. In: BAKHTIN, M. Estética da criação verbal. 6. ed. Tradução de Paulo Bezerra. São Paulo: Martins Fontes, 20Irb, p. 3-I86.

BAKHTIN, M. “Apontamentos de I970-I97I”. In: BAKHTIN, M. Estética da criação verbal. 6. ed. Tradução de Paulo Bezerra. São Paulo: Martins Fontes, 20IIc, p. 367-392.

BAKHTIN, M. (VOLOCHINOV). Marxismo e Filosofia da Linguagem. 9. ed. São Paulo: Hucitec, I999 [I929].

BAKHTIN, M. Problemas da poética de Dostoiévski. Tradução de Paulo Bezerra. 5. ed. Rio de Janeiro: Forense Universitária, 20I3.

BARTHES, Roland. Essais Critique. Paris: Editions du seuil, I971.

BAUMAN, Richard (ed.). Folklore, Cultural Performances and Popular Entertainments. NewYork, Oxford, Oxford University Press, I992.

BAUMAN, Richard; BRIGGS,Charles Leslie., I990. Poetics and Performance as Critical Perspectives on Language and Social Life. In Annual Review of Anthropology V. I9, Bernard J. Siegel, ed. Palo Alto, Annual Reviews, I990

BAUMAN, Richard. Fundamentos da performance. Revista Sociedade e Estado, v. 29, n. 3, set./dez. 2014 .

BOCH, F.; GROSSMANN, F. "Referir-se ao discurso do outro: alguns elementos de comparação entre especialistas e principiantes”. Revista Scripta, v. 6, n. ㅍ. Belo Horizonte: PUC Minas, 2002.

BRAIT, Beth. Bakhtin: outros conceitos-chave. São Paulo, 2016.

BRAIT, Beth; MELO, Rosineide de. Enuncionado/enunciado concreto/enunciação. In: BRAIT, Beth. Bakhtin: outros conceitos-chave. São Paulo, 2016.

CAMARGO, R. C.; REINATO, E. J.; FERNANDES, H. S. Performances Culturais. São Paulo: Hucitec Goiânia, GO: PUC-GO, $20 I I$. 
CAMARGO, R. C. "A crítica e a crítica genética: diálogos sobre o entendimento do espetáculo teatral”. Gestos, v. 4, p. 13-32, abr. 2007. Versão ampliada em: https://www.academia.edu/I68182/2008_Teatro_e_Recepção._A_Crítica_e_a_Crítica_Genética._Diálogos_sobre_o_entendimento_do_espetáculo_teatral. 2008.

CARLSON, Marvin. Performance - Uma introdução crítica. Belo Horizonte: Ed. UFMG, 2010.

CARNAVAL. Revista Fon Fon, ano III, n. 8, I8 de fevereiro de I909. [HYPERLINK http://objdigital.bn.br/ acervo_digital/div_periodicos/fonfon/fonfon_I909/fonfon_I909_008.pdf ]. Figura I.

CAVALCANTI, Maria Laura Viveiros de Castro. O rito e o tempo: ensaios sobre o carnaval. Rio de Janeiro: Civilização Brasileira, I999.

COSTA, Haroldo. Ioo anos de carnaval no Rio de Janeiro. Rio de Janeiro: Irmãos Vitale, 2000.

COUTINHO, A. Introdução à literatura no Brasil. 9. ed. Rio de Janeiro: Civilização Brasileira, I978.

COSTA. Cristiane. Pena de aluguel: escritores jornalistas no Brasil I904-2004. São Paulo: Companhia, 2005.

CUNHA, Maria Clementina Pereira. Ecos da folia: uma história social do carnaval carioca entre I880 e I920. São Paulo: Companhia das Letras, 200I.

CUNHA, Maria Clementina Pereira. Carnavais e outras f(r)estras: ensaios de história social da cultura. Campinas-SP: Editora da Unicamp, Cecult, 2002.

DAMATTA, Roberto. A Casa e a Rua. Rio de Janeiro: Rocco, I997.

DAMATTA, Roberto. Carnavais, malandros e heróis: para uma sociologia do dilema brasileiro. Rio de Janeiro: Rocco, 1997.

DISCINI, Norma. Carnavalização in BRAIT, Beth. Bakhtin: outros conceitos-chave. São Paulo, $\quad 2016$.

DUVIGNAUD, Jean. Festas e Civilizações. Rio de Janeiro: Ed. Tempo Brasileiro, I983.

EDMUNDO, Luís. O Rio de Janeiro do meu tempo. Rio de Janeiro: Conquista, 2003 [I938]. 3V

EVREINOFF, Nicolas. El teatro en la vida. Santiago de Chile, I936.

FARIA, Marcelo Fecunde de. Zé Pereira: a performance carnavalesca em Itaberaí-GO. 20I5. I76 f. Dissertação. (Mestrado em Performances Culturais). Universidade Federal de Goiás, Goiás.

FARIA, Marcelo Fecunde de. Zé Pereira em Itaberaí-GO - mascarados. Fotografia. 20I4.

FARIA, Marcelo Fecunde de. Zé Pereira em Itaberaí-GO. Tocadores de bumbo. Fotografia. 2014.

FAZENDA, José Vieira. Antiqualhas e Memórias do Rio de Janeiro. Rio de Janeiro: Documenta Histórica/ IHGB/Instituto Light, 20II, $5 \mathrm{v}$.

FÉRAL, J. Por uma poética da performatividade: o teatro performativo. Sala Preta ECA/USP, v. 8, p.I972IO, 2008.

FÉRAL, Josette. Além dos limites: teoria e prática do teatro. São Paulo: Perspectiva, 2015.

FÉRAL, Josette. Acerca de la teatralidad. Buenos Aires: Editorial Nueva Generación, 2003.

FERNANDES, Silvia. “Teatralidades contemporâneas”. In: WERNECK, Maria Helene; BRILHANTE, Maria João (Orgs). Texto e Imagem: estudo de teatro. Rio de Janeiro: 7Letras 2009.

FERREIRA, Felipe. O livro de ouro do carnaval brasileiro. Rio de Janeiro: Ediouro, 2004.

FERREIRA, Procópio. O ator Vasques - o homem e a obra. Rio de Janeiro: Serviço Nacional de Teatro, I979 [I939].

FIORIN, José Luiz. Introdução ao pensamento de Bakhtin. São Paulo: Ática, 2006.

FREUD, S. Esboço de psicanálise. In: Edição Standard Brasileira das Obras Psicológicas Completas de Sigmund Freud (v. XXIII, p. I68-245). Rio de Janeiro: Imago, I955.

GONÇALVES, Renata de Sá. Os ranchos pedem passagem: o carnaval no Rio de Janeiro do começo do Século XX. Rio de Janeiro: Secretaria Municipal das Culturas, Coordenadoria de Documentação e Informação cultural, Gerência de Informação, 2007.

GOFFMAN, Erving. A representação do eu na vida cotidiana. Rio de Janeiro: Editora Vozes, 20I4 [I959]. 
HERMENEGILDO, A. Juegos dramáticos de la locura festiva: pastores, simples, bobos y graciosos del teatro clásico español. Barcelona: Oro Viejo, I995.

JUNIOR, Roberto Abdala. O Cinema é uma outra história: Considerações sobre o Cinema nas aulas de história. 2005. Disponível em: http://www.bocc.ubi.pt/pag/junior-roberto-cinema-outra-historia. pdf. Acesso em: 4 nov. 2019.

LANGDON, Esther Jean; PEREIRA, Éverton Luís. (org.) Rituais e performances: iniciações em pesquisa de campo. Florianópolis: UFSC, 2012.

LIGIÉRO, Zeca. Performance e Antropologia de Richard Schechner. Mauad: Rio de Janeiro, 2012.

LOPES, Antônio Herculano. Performance e História (ou Como a onça, de um salto, foi ao Rio do princípio do século e ainda voltou para contar a história). Rio de Janeiro: Fundação Casa Rui Barbosa, I994.

MALHOA, José. Volta da feira (Chegada do Zé Pereira à Romaria). Óleo sobre tela, I905. Figura 3. Disponível em: https://br.pinterest.com/pin/502855II4639266I3I/?lp=true. Acesso em: nov. 2019.

MORAES, Eneida de. História do carnaval carioca. Rio de Janeiro: Record, I987.

MUSEU DO ZÉ PEREIRA. Bloco do Zé Pereira em São Bento do Sapucaí-SP. Figura 6. Arquivo web do grupo. Facebook: @museudozepereira. Disponível em: www.facebook.com/museudozepereira. Acesso em: I nov. 20I9:

PAVIS, P. Dicionário de teatro. 3. ed. Tradução de: Maria Lúcia Pereira et al. São Paulo: Perspectiva, I996.

PACHECO, Armando. Zé-pereira. Desenho. In: EDMUNDO, Luís. O Rio de Janeiro do meu tempo. Rio de Janeiro: Conquista, I957. 3v

PINHEIRO, Marlene M. Soares. A travessia do avesso: sob o signo do carnaval. São Paulo: ANNABLUME, I995.

QUEIROZ, Maria Isaura Pereira de. Carnaval brasileiro: o vivido e o mito. São Paulo: Brasiliense, I999.

SCHECHNER. Richard. Performance Theory. London: Routledge, I988.

VALENÇA, Raquel; VALENÇA, Suetônio Soares. Serra, Serrinha, Serrano: Império do Samba. Rio de Janeiro: José Olympio, I98I.

ZÉ PEREIRA DE PORTUGAL. Arquivo digital. Disponível em: http://www.imagesofportugal.net/media/ 8d5863fC-II5a-IIe3-95ed-d38896f35Ie5-traditional-drummers-zes-pereiras-acting-during-the-our-lady. Acesso em: nov. 2019.

ZUMTHOR, Paul. Performance, recepção e leitura. São Paulo: Cosac Naify, 2007. 
